\title{
Thermal transfer in a multilayer plate with source of metabolic heat
}

\author{
Mikhail A. Ulchiekov ${ }^{1, *}$, Tatyana N. Nemova ${ }^{1}$ \\ ${ }^{1}$ National Research Tomsk Polytechnic University, 634050 Tomsk, Russia \\ ${ }^{2}$ Tomsk State University of Architecture and Building, 634000 Tomsk, Russia
}

\begin{abstract}
In this article heat transfer in a multi-layered plate (human skin and thermal insulation) with various boundary conditions is considered. This allows you to justify the choice of air temperature in the production premises.
\end{abstract}

\section{Introduction}

The air temperature $\left(T_{A}\right)$ in the production room is the most significant factor during design heating and ventilation systems, the TA value is selected in such a way as to ensure the requirements of the "thermal comfort" of the worker are met [1]. But by now the choice of $T_{A}$ is based on empirical data on human sensations and this is "subjective" (it is assumed that TA should be in the range $18{ }^{\circ} \mathrm{C}$ to $24^{\circ} \mathrm{C}$ [2-4]), and the mathematical justification is "not enough" described [5]. In this connection, the mathematical modelling of heat transfer within the framework of the heat conduction model (which allows us to describe the process of heat exchange of a person with the environment quite accurately) is an actual research direction.

The purpose of this work is numerically research of the heat transfer within a multilayer plate (layers of human skin and external thermal insulation), with different heat exchange options at the boundaries of the layers.

\section{Formulation of the problem}

In this paper is considered two options of formulation the problem: the temperature of the main part of the human body $T_{1}$ varies in a small range of $35.5-35.8^{\circ} \mathrm{C}$; from the surface of the human body the heat flows and equal to $q=M / A$ [5] (M is the part of metabolic heat leaving the surface of the skin, and $\mathrm{A}$ is the area of the human body).

Human skin is considered as a natural insulation consisting of subcutaneous fat (thickness $\Delta_{1}$ ), dermis (thickness $\Delta_{2}$ ), epidermis (thickness $\Delta_{3}$ ) [6]. Also, the outer insulation layer adheres to the surface of the skin, which includes an air layer (thickness $\Delta_{4}$ ) and clothing (thickness $\Delta_{5}$ ).

\footnotetext{
* Corresponding author: ulchieckovmihail@mail.ru
} 
It was assumed that the temperature of the air in the production premises is constant and does not change with time $\left(T_{A}=\right.$ const $)$, and heat exchange on the outer surface of clothing occurs due to natural convection and thermal radiation.

As a parameter that serves as a "comfort characteristic" is used the surface temperature of the $T_{S}$ kin. On the basis of the theory [1] it is assumed that the worker feels "comfort" at $T_{S}=306 \div 307 \mathrm{~K}$.

Mathematical statement of the first problem:

$$
\left\{\begin{array}{l}
\rho_{1} c_{1} \frac{\partial T_{1}}{\partial t}=\lambda_{1} \frac{\partial^{2} T_{1}}{\partial x^{2}}, 0<x<x_{1} ; \\
\rho_{2} c_{2} \frac{\partial T_{2}}{\partial t}=\lambda_{2} \frac{\partial^{2} T_{2}}{\partial x^{2}}, x_{1}<x<x_{2} \\
\rho_{3} c_{3} \frac{\partial T_{3}}{\partial t}=\lambda_{3} \frac{\partial^{2} T_{3}}{\partial x^{2}}, \quad x_{2}<x<x_{3} ; \\
\rho_{4} c_{4} \frac{\partial T_{4}}{\partial t}=\lambda_{4} \frac{\partial^{2} T_{4}}{\partial x^{2}}, x_{3}<x<x_{4} \\
\rho_{5} c_{5} \frac{\partial T_{5}}{\partial t}=\lambda_{5} \frac{\partial^{2} T_{5}}{\partial x^{2}}, x_{4}<x<L
\end{array}\right.
$$

Here $\rho_{i}, \lambda_{i}, c_{i}$ - the density, thermal conductivity and specific heat of the material system of $i$-layer, $T i$ - current temperature value $(i=1 \ldots 5)$.

The boundary condition of the first kind $\left(T_{1}=309 \mathrm{~K}\right)$ is given on the left boundary $x=0$, heat transfer due to natural convection and radiation is taken into account at $x=L$, boundary conditions of the fourth kind (equality of temperatures and heat fluxes) are given on the interfaces of the layers.

The initial and boundary conditions are:

$$
\begin{aligned}
& x=0: T=T_{1}, T_{1}=\text { const } ; \\
& x=x_{1}: \lambda_{1} \frac{\partial T_{1}}{\partial x}=\lambda_{2} \frac{\partial T_{2}}{\partial x}, T_{1}=T_{2} ; \\
& x=x_{2}: \quad \lambda_{2} \frac{\partial T_{2}}{\partial x}=\lambda_{3} \frac{\partial T_{3}}{\partial x}, T_{2}=T_{3} ; \\
& x=x_{3}: \quad \lambda_{3} \frac{\partial T_{3}}{\partial x}=\lambda_{4} \frac{\partial T_{4}}{\partial x}, T_{3}=T_{4} ; \\
& x=x_{4}: \quad \lambda_{4} \frac{\partial T_{4}}{\partial x}=\lambda_{5} \frac{\partial T_{5}}{\partial x}, T_{4}=T_{5} ; \\
& x=L: \quad \lambda_{5} \frac{\partial T_{5}}{\partial x}=\alpha\left(T_{L}-T_{A}\right)+\varepsilon \sigma\left(\left(T_{L}\right)^{4}-\left(T_{A}\right)^{4}\right) ; \\
& t=0: \quad T_{1}=T_{1}^{0}, T_{2}=T_{2}^{0}, \ldots . ., T_{x 1}=T_{x 1}^{0}, 0<x<x_{3} ; \\
& \quad T=T_{0}^{A}, x_{3}<x<x_{4} ; \\
& T=T_{0}^{c l}, x_{4}<x<L ;
\end{aligned}
$$

Here $\alpha$ - heat transfer coefficient, $\varepsilon$ - reduced emissivity surface of human skin, $\sigma$ - Stefan-Boltzmann constant.

The mathematical model of the second version of the formulation with the corresponding initial boundary and initial conditions has the form: 


$$
\begin{aligned}
& \left\{\begin{array}{l}
\rho_{4} c_{4} \frac{\partial T_{1}}{\partial t}=\lambda_{4} \frac{\partial^{2} T_{1}}{\partial x^{2}}, 0<x<x_{1} ; \\
\rho_{5} c_{5} \frac{\partial T_{2}}{\partial t}=\lambda_{5} \frac{\partial^{2} T_{2}}{\partial x^{2}}, x_{1}<x<L ;
\end{array}\right. \\
& \begin{array}{l}
x=x_{2}: \quad \lambda_{4} \frac{\partial T_{4}}{\partial x}=\lambda_{5} \frac{\partial T_{5}}{\partial x}, T_{1}=T_{2} ; \\
x=0: \quad-\lambda_{4} \frac{\partial T_{4}}{\partial x}=q_{1} ; q_{1}=M / A ;
\end{array} \\
& \begin{array}{c}
x=L: \quad \lambda_{5} \frac{\partial T_{5}}{\partial x}=\alpha\left(T_{L}-T_{B}\right)+\varepsilon \sigma\left(\left(T_{L}\right)^{4}-\left(T_{B}\right)^{4}\right) ; \\
t=0: T=T_{0}^{6}, x_{3}<x<x_{4} ; \\
T=T_{0}^{o d}, x_{4}<x<L ;
\end{array}
\end{aligned}
$$

The main difference between these two statements is that in the first one only layers of external isolation are considered, and a boundary condition of the second kind $(q=M / A)$ is given at the boundary $x=0$.

The heat transfer coefficient was calculated by the criterion eqution for the conditions of natural convection near a plane wall [7]:

$$
\begin{gathered}
N u^{1 / 2}=0.825+\frac{0.387 \cdot R a^{1 / 6}}{\left[1+\left(\frac{0.492}{\operatorname{Pr}}\right)^{9 / 16}\right]^{8 / 27}} ; \\
R a=\operatorname{Pr} \cdot G r ; \\
G r=\frac{\beta \cdot l^{3} \cdot g \cdot\left(T_{L}-T_{B}\right)}{v} ; \\
R a=\operatorname{Pr} \cdot G r ; \\
G r=\frac{\beta \cdot l^{3} \cdot g \cdot\left(T_{L}-T_{B}\right)}{v} ;
\end{gathered}
$$

Here Gr - the number of Grazgof, 1 - a characteristic size (height of a man), $v$ - kinematic viscosity coefficient (air), $\beta$ - the temperature coefficient of volume expansion of the air.

From the determination of the Nusselt number [8]:

$$
\alpha=\frac{N u \cdot \lambda}{l}
$$

At this stage of the research it was assumed that the person is at rest (the heat given off by evaporation is small [8], because $M / A$ - for a resting state of $\left.50 \mathrm{~W} / \mathrm{m}^{2}\right)$ :

$$
Q_{u}=0.49 \cdot(M / A \cdot(1-\eta)-50)
$$

The system of differential equations with appropriate initial and boundary conditions is solved by finite difference method, using an algorithm [8,9] developed for solving heat transfer problems in the areas of multi-layer discontinuous thermal conductivity.

At the solution of the problem the temperature dependence of thermal characteristics of materials and layer materials are not taken into consideration, since the latter was only a change from $1 \mathrm{~K}$ to $10 \mathrm{~K}$.

\section{Results of numerical modelling}

When modelling TA changed in the really possible range (from $277 \mathrm{~K}$ to $304 \mathrm{~K}$ ), the parameters of clothing varied. 
The thermo physical characteristics of the layers of the system are accepted in accordance with the data $[11,12,13]$ :

$$
\begin{aligned}
& \lambda_{1}=0.2 \mathrm{~W} / \mathrm{m} \cdot K, \lambda_{2}=0.45 \mathrm{~W} / \mathrm{m} \cdot \mathrm{K}, \lambda_{3}=0.21 \mathrm{~W} / \mathrm{m} \cdot \mathrm{K}, \lambda_{4}=0.024 \mathrm{~W} / \mathrm{m} \cdot \mathrm{K}, \\
& \lambda_{5}=0.03 \mathrm{~W} / \mathrm{m} \cdot K \\
& \rho_{1}=850 \mathrm{~kg} / \mathrm{m}^{3}, \rho_{2}=1000 \mathrm{~kg} / \mathrm{m}^{3}, \rho_{3}=1200 \mathrm{~kg} / \mathrm{m}^{3}, \rho_{4}=1.2 \mathrm{~kg} / \mathrm{m}^{3}, \rho_{5}=120 \mathrm{~kg} / \mathrm{m}^{3} \\
& c_{1}=2250 \mathrm{~J} / \mathrm{kg} \cdot K, c_{2}=3200 \mathrm{~J} / \mathrm{kg} \cdot K, c_{3}=3600 \mathrm{~J} / \mathrm{kg} \cdot K, \\
& c_{4}=1005 \mathrm{~J} / \mathrm{kg} \cdot \mathrm{K}, c_{5}=2260 \mathrm{~J} / \mathrm{kg} \cdot \mathrm{K},
\end{aligned}
$$

The thicknesses of the layers of skin accepted in accordance with [7]:

$$
\Delta_{1}=0.013 \mathrm{~m}, \Delta_{2}=0.0005 \mathrm{~m}, \Delta_{3}=0.001 \mathrm{~m}
$$

Typical initial temperatures:

$$
T_{0}^{c l}=301 K, T_{0}^{a}=303 K, T_{0}^{x 1}=307 .
$$

The duration of the modeled process chosen within the limits: $t=7000 \mathrm{~s}$.

The degree of emissivity of human skin [13]:

$$
\varepsilon=0.7 \text {. }
$$

Dependences of skin surface temperature on time at different ambient temperatures for the adopted formulations of the problem are shown in Fig. 1. It is established that the $T_{S}$ decreases significantly faster and depends more on $T_{A}$ in a system with a boundary condition of the second kind.

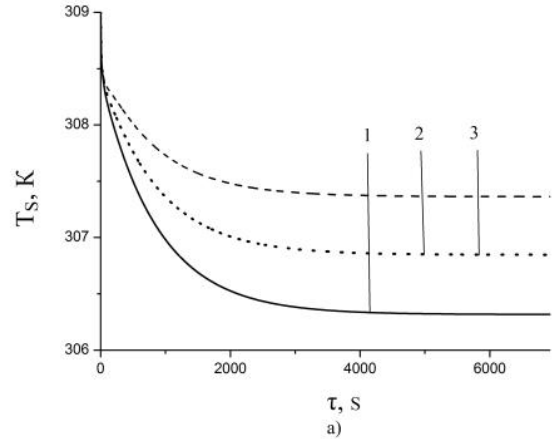

a)

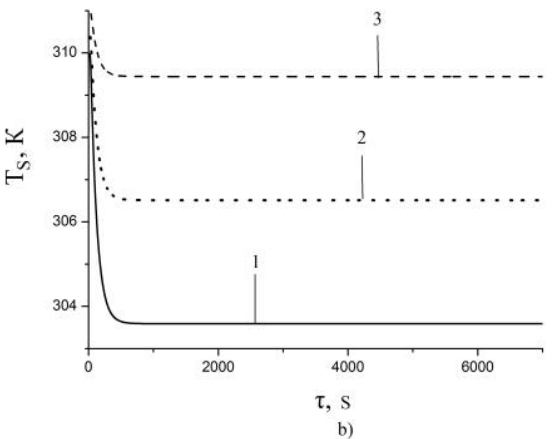

b)

Fig. 1. Dependence of $T_{S}$ on time at: $1-T_{A}=291 \mathrm{~K} ; 2-T_{A}=294 \mathrm{~K} ; 3-T_{A}=302 \mathrm{~K}$ : a) a first-kind boundary condition for $\mathrm{x}=0$; $\mathrm{b}$ ) a boundary condition of the second kind for $\mathrm{x}=0$.

Dependences of skin surface temperature on time at different ambient temperatures for the adopted formulations of the problem are shown in Fig. 1. It is established that the $T_{S}$ decreases significantly faster and depends more on $T_{A}$ in a system with a boundary condition of the second kind.

"Comfortable" air temperatures for easily dressed people are given in [1], obtained in experimental studies. It was found that $T_{A}$ is in the range of $17-24{ }^{\circ} \mathrm{C}$. Dependences of the surface temperature of the heat supply object on $T_{A}$ are shown in Fig. 2 It can be concluded that a mathematical model with a boundary condition of the first kind (Fig. 2 a, 1, 2) at $x=0$ corresponds more exactly to experimental data than with a boundary condition of the second kind. 


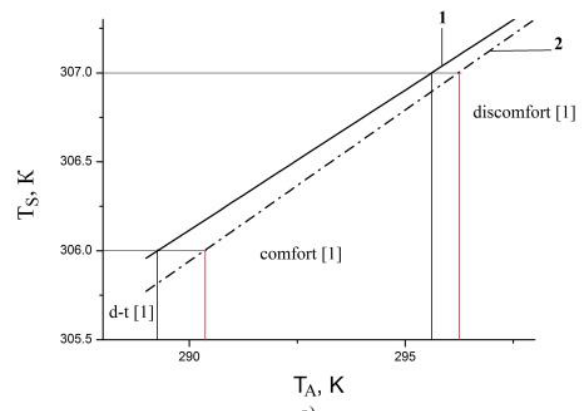

a)

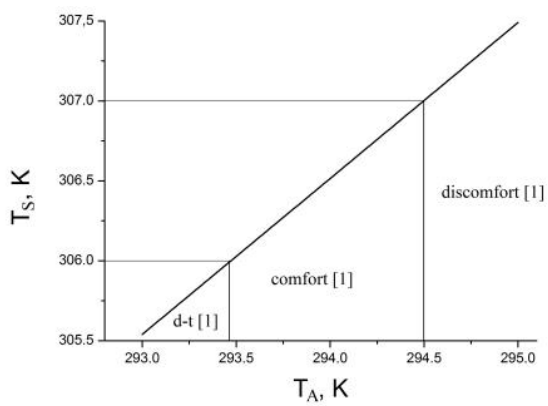

b)

Fig. 2. Dependence of $T_{S}$ on ambient temperature (single-layer wool clothing): $1-T_{A}=291 \mathrm{~K} ; 2$ $T_{A}=294 \mathrm{~K} ; 3-T_{A}=302 \mathrm{~K}$ : a) a first-kind boundary condition for $\mathrm{x}=0(1$ - results obtained in this paper, 2 - obtained in [15]); b) a boundary condition of the second kind for $\mathrm{x}=0$.

The thickness of clothes plays a big role in choosing the air temperatures of production premises. The connection between the "comfort" $T_{A}$ and the thickness of the layer of external thermal insulation (woollen clothing) for the two tasks discussed above is shown in Fig. 3. It is established that for a system with a boundary condition of the second kind at $\mathrm{x}=0$, the influence of the clothing thickness on the "comfort" $T_{A}$ is greater than for conditions of the first kind at this boundary.

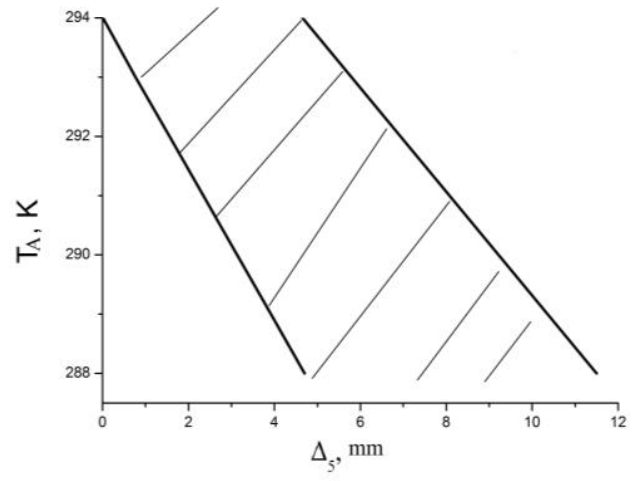

a)

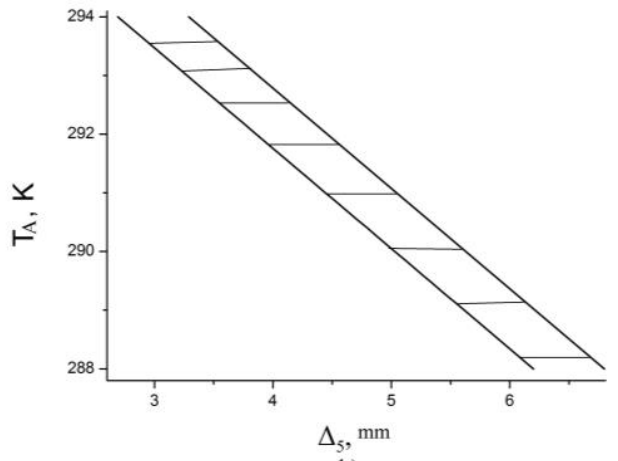

b)

Fig. 3. Dependence of "comfortable" air temperature on the thickness of wool clothing: a) a first-kind boundary condition for $\mathrm{x}=0$; $\mathrm{b}$ ) a boundary condition of the second kind for $\mathrm{x}=0$.

\section{Main results and conclusions}

1. The problems of thermal conductivity for the system "heat supply object - the layer of thermal insulation - the external environment" with allowance for natural convection and radiation at the external boundary with boundary conditions of the first and second kind at $\mathrm{x}=0$ are solved.

2. Dependences of the surface temperature of the skin on the ambient temperature for the two formulation of the problem are obtained. It is established that conditions of the first kind provide a better fit to the experimental data [1].

3. The connection of "comfortable" air temperature and the thickness of woollen clothing is revealed.

The work was supported by the Russian Federation President's grant (NSH project -7538.2016.8). 


\section{References}

1. V. N. Platova, Biologia, 8 (2008) [in Russian]

2. P. Domingues, P. Carreira, R. Vieira, W. Kastner, Comp. St. Int. 45 (2016)

3. M. Wallance, R. McBride., P. Mhaskar, , J. House, T. Salsbury, Ch. Eng. Sc. Ener. 69 (2012)

4. M. Taleghani, M. Tenpierik, A. Dobbelsteen, Ren. Sust. En. R. 26 (2013)

5. A. Machkashi, L. Bahdidi, Radiant heating (Stroyizdat, Moscow, 1985)

6. F. Xu, T. J Lu, K. A., Sef. Acta Mech. S. 24 (2008)

7. Robert E. Simons, Electroning cooling, 6 (2001)

8. F. P. Incropera, D. P. DeWitt, Fundamentals of Heat and Mass Transfer (John Wiley and Sons, NY, 1985)

9. O.V. Vysokomornaya, G.V. Kuznetsov, P.A. Strizhak, Rus. J. Ph. Ch. B. 5 (2011)

10. V.L. Strakhov, A.N. Garashchenko, G.V. Kuznetsov, V.P. Rudzinskii, Comb., Exp. Sh. W. 37 (2001)

11. I.K. Kikoin, Tables of physical quantities (Atomizdat, Moscow, 1976) [in Russian]

12. A.P. Babichev, A.P. Babushkin, A.M. Bratkovsky Physical values, (Eneroatomizdat, Moscow, 1991) [in Russian]

13. M.V. Nazarova, S. Yu. Boyko, Modern problems of s. and ed. 5 (2009)

14. U. Kukelev, A. Ustinov, Resources and Technology, 3 (2005)

15. M.A. Ulchiekov, E.E. Bulba, MATEC Web of Conf. 8 (2017) 